\title{
On the Benefits of Party Competition*
}

\author{
Dan Bernhardt \\ Department of Economics \\ University of Illinois \\ Urbana Champaign
}

\author{
Larissa Campuzano \\ Department of Economics \\ University of Rochester
}

\author{
Francesco Squintani \\ Department of Economics \\ University College, London
}

August, 2005

\begin{abstract}
We study the role of parties in a citizen-candidate repeated-elections model where voters have incomplete information. We identify a novel "party competition effect." Compared with "at large" selection of candidates, party selection makes office-holders more willing to avoid extreme ideological stands. Politicians follow party discipline, even in absence of a party-controlled reward mechanism. Voters of all ideologies benefit from the party-competition effect, which thus provides a novel rationale for political parties. The mere existence of a competing party, discourages elected officials from drifting into extremism. When politicians have an (imperfect) informational advantage over voters, we additionally find a "party screening" effect. Parties select moderate candidates, because they anticipate that their candidate's ideological record can be verifiably disclosed through campaigning. Under reasonable functional assumptions, all voters benefit from party screening.
\end{abstract}

\footnotetext{
${ }^{*}$ We thank the audiences of seminars at the Wallis Institute, Rochester University, at Southampton University, of the 2004 Workshop in Political Economy at Stony Brook, the 2004 Political Economy Workshop at Vienna, the 2005 Society for Advancement of Economic Theory Conference in Vigo, and especially Jim Snyder, for their comments. Nate Anthony helped significantly in this research.
} 


\section{Introduction}

This paper studies the role of party competition in a citizen-candidate repeated-elections model where voters have limited information about candidates ideologies, and where incumbents' past actions help voters predict their future choices if re-elected. We contrast party selection of candidates with atlarge selection in absence of parties. For politicians, we ask: Would politicians be more representative of their constituency with party or at-large selection? Would they be more or less willing to take ideological stands? For voters, we ask: Would party selection induce voters to set more demanding standards of representation on incumbents for them to win re-election? Would more incumbents lose with party or at-large selection of challengers? Would voters be better off with party selection than with at-large selection? For parties we ask: Can parties play an active role in screening candidates? What type of candidates would they select? Is such screening beneficial to voters?

We first abstract from the role of parties in screening their candidates, and derive general predictions about how the voters' choices and the office-holders' choices are affected by parties. We identify a novel "party competition" effect: Party competition makes office-holders more reluctant to take extreme ideological stands, and induces voters to select more demanding standards for re-election. We then refine our predictions when politicians have an (imperfect) informational advantage over voters, identifying a "party screening" effect: parties select moderate candidates. Finally, we derive the implications for welfare. We find that the 'party-competition' effect is beneficial to voters of all ideologies. Under reasonable functional assumptions, we also find that party screening is beneficial to all voters. Hence, our analysis provides new rationales for political parties.

Our model is as follows. Rational, forward-looking citizens, be they voters, electoral candidates or elected representatives, care about the policy choices of representatives in office. Each period, an incumbent faces an electoral challenge from an opposing candidate. Voters have limited information about the challenger's ideology, but can use the incumbent's past actions in office to make inferences 
about her ideology, and hence, her actions if re-elected. ${ }^{1}$ We maintain the fundamental tenet of citizen-candidate models that candidates for office cannot make credible promises. We contrast outcomes when the challenger is drawn at random from the entire spectrum of ideologies "at large", with those that obtain when the challenger is drawn from a party representing the wing of the ideological space "opposite" from the incumbent.

Given standard assumptions the median voter is decisive and sets a simple retrospective voting rule: vote for the incumbent candidate if and only if the incumbent's policy is sufficiently moderate. An incumbent with a sufficiently moderate ideology can represent his own ideology and win reelection. All other winning incumbents take positions as close to their ideologies as they possibly can and still be re-elected. Voters use this information to update their beliefs about an incumbent's ideology: The location of the marginal re-elected incumbent leaves the median voter indifferent between re-electing the incumbent and selecting an untried challenger.

The "party competition" effect materializes because an incumbent fears being replaced by a challenger from the opposing party by more than she fears being replaced by a challenger from "at large" - the incumbent's own ideology is further from the likely ideology and location of a challenger selected from the opposing party. As a result, ceteris paribus, with party selection, an incumbent is more willing to compromise and adopt positions closer to the median voter's preferred position in order to win re-election. In turn, party selection raises the random value of an untried politician to the median voter, causing the median voter to set more demanding standards for re-election. This "party competition" effect provides a fully endogenous theory of party discipline: office-holders are willing to follow party lines, even though there is no party-controlled reward mechanism. Incumbents avoid extreme ideological stands and take the responsibility not to lose the elections.

We then show that party selection of challengers also reduces turnover of incumbents. This result is far from immediate as the indirect effect of party selection on re-election standards - voters set more demanding standards for re-election - is to increase turnover. Effectively, we show that the

\footnotetext{
${ }^{1}$ Most models of candidate location ignore differences between incumbents and challengers. Yet, these differences must be important - in practice, incumbents generally win re-election. Our model highlights one key difference between incumbents and challengers: Voters typically know much more about incumbents than challengers, who are usually untried in the office for which they are running.
} 
direct effect on turnover of the increased willingness of extreme candidates to restrict location in the face of party selection dominates the indirect effect of the changed re-election standards. Because of this self-induced "party discipline", in equilibrium, incumbents are more likely to be re-elected with party selection than with at-large selection.

Our welfare analysis puts together the implications of these observations to show that the "party competition" effect benefits all voters. The median voter values the greater willingness of officeholders to compromise and adopt moderate positions closer to the median policy to win re-election; and all other voters benefit from the reduction in the per-period variance in adopted policies, and the reduced turnover, which lowers the variability over time in policies adopted by elected representatives.

We then extend the analysis to consider the possibility that politicians (e.g., candidates and parties) have an (imperfect) informational advantage over voters. For simplicity, we assume that information is coarse: politicians can only assess and reveal whether a candidate is moderate or extremist. This coarse information can be verifiably disclosed through campaigning, reflecting that it may be revealed through past public stands on policy issues. We find that parties select moderate candidates. This "party screening" effect reinforces the "party competition" effect; it does not substitute for it. In equilibrium, parties anticipate that if they select extremist challengers, the incumbent will successfully campaign against them and win re-election. Under the natural model specification that ideologies are uniformly distributed and loss functions are homogeneous, all voters benefit from party screening that identifies moderate candidates.

Before proceeding with the formal analysis, we emphasize the parsimonious nature of our model of parties. In our model, parties do not pool financial resources. They do not exercise party discipline, nor dictate party lines. Parties have no control whatsoever on elected candidates' policy choices. There is no partisanship: citizens do not care about party identity per se, but only about the policies adopted by elected representatives. We obtain the "party competition" effect by imputing to parties only the ability to aggregate citizens with like-minded political views. The "screening effect" only requires that politicians have slightly better information about potential representatives, and that parties can endorse a candidate. With a broader theory of parties that enriches the set of abilities 
and functions of parties in the political arena, one would likely uncover expanded roles for parties.

This paper is presented as follows. After the literature review, section 3 analyzes our base citizencandidate repeated election model. Section 4 enriches the model to allow politicians to have better information on candidates' ideology than voters. Section 5 concludes. As is customary, most of the formal proofs are in the appendix.

\section{Literature Review}

Our analysis is most closely related to Duggan (2000) and to Bernhardt et al. (2004). Duggan (2000) develops the basic theory of repeated citizen-candidate election with incomplete information about candidates' policy preferences. Bernhardt et al. (2004) study related issues when politicians face term limits, and more senior politicians can obtain "pork transfers" for their districts from districts with less senior politicians. ${ }^{2}$ Banks and Duggan (1999) extend Duggan's (2000) analysis to allow for multiple ideological dimensions. Bernhardt and Ingberman (1985) is the first paper to consider the consequences of informational differences between incumbents and challengers. Most of the literature on informational differences between incumbents and challengers focuses on legislative ability rather than ideology. Banks and Sundaram (1993) develop a dynamic model in which representatives exert effort to represent their constituency. Over time, voters learn which representatives are lazy, and vote them out, so a smaller fraction of more senior incumbents lose. In a similar vein, Austen-Smith and Banks (1991) and Ferejohn (1986) consider dynamic games in which representatives dislike exerting effort.

Our ideas of studying parties within the repeated citizen-candidate election with incomplete information framework owes to the original intuition by Downs (1957) that party labels provide voters with information about candidates. Since Fiorina (1981) and Lindbeck and Weibull (1993), there is substantial evidence that voters learn about the policy positions of candidates from party labels. More recently, Snyder and Ting (2002) found that party dummies explain much of the variation in the voters' placements of candidates on a left-right scale. These empirical findings have

\footnotetext{
${ }^{2}$ Relatedly, Reed (1994) solves an example featuring moral hazard and adverse selection in the provision of a public good where there is a term limit of two terms. Banks and Sundaram (1998) and Reed (1989) consider related adverse selection models.
} 
fostered recent theoretical analyses. Snyder and Ting (2002) study the relationship between platform choices and the information power of party labels. Ashworth and Bueno de Mesquita (2004) provide a formal account where party discipline, candidate affiliation, and ideological homogeneity are all determined endogenously within a strategic electoral-legislative setting. The informational role of parties is highlighted in our analysis by the 'screening effect'. In contrast to these papers, we adopt a minimalist approach to parties - our parties do not dictate party lines. Our 'party competition' effect is driven by the possibility of alternance in office of politicians from opposing parties. The role played by information in party labels is minimal.

Related to our study on some of the benefits of the party system is the literature on endogenous party formation. Morelli (2004) studies a model where parties facilitate coordination among voters and allow candidates to commit to policies. He finds conditions under which proportional representation gives rise to more parties than the plurality rule. Jackson and Moselle (2001) study a legislative voting game where decisions are made over both ideological and distributive dimensions. Parties form because it is assumed that elected representatives can commit to enforce their party agreements. Levy (2002) focuses on the role of parties in insuring the credibility of policy commitments. She shows that the commitment role of parties is most effective when the policy space is multi-dimensional. Feddersen (2001) explains party formation as coalitions of voters, whereas in Osborne and Tourky (2003), parties arise in legislatures due to economies of scale. Persson, Roland and Tabellini (2003) study a model in which electoral institutions endogenously determine party fragmentation. In contrast to these papers, we do not address how parties are formed. Rather, we take the existence of two parties as given, and show that all voters benefit when the pool of politicians partitions into two parties with opposing ideologies.

\section{The 'Party Competition Effect'}

There is an interval $[-a,+a]$ of citizen candidates, each indexed by her private ideology $x \in[-a,+a]$. Ideologies are private information to the candidates. Ideologies are distributed across society according to the c.d.f. $F$, with an associated single-peaked density $f$, that is symmetric about the median 
voter's ideology, $x=0$. At time 0 , an office holder is randomly determined. In any period $t$, an office-holder with ideology $x$ selects a policy $p(x) \equiv y \in[-a,+a]$. The time- $t$ utility of a citizen $x$ depends on the implemented policy $y$, according to a symmetric, single-peaked loss function $L_{x}(y)=l(|x-y|)$, where $l$ is $\mathcal{C}^{2}$, and $l^{\prime}<0, l^{\prime \prime} \leq 0$. We normalize $l(0)=0$ without loss of generality. Note that $L$ satisfies the single-crossing property: $L_{x}^{\prime}$ is increasing in $x$. Period utilities are discounted with factor $\delta<1 .^{3}$

We focus on symmetric, stationary and stage-undominated perfect Bayesian equilibrium (PBE). A stationary policy strategy $p$ prescribes that at any time $t$, the policy $y$ selected by an office-holder depends only on his ideology $y$, regardless of $t$ and of the history of play at time $t$. The policy strategy is symmetric if $p(x)=-p(-x)$. If representatives adopt symmetric stationary strategies, stage-undominated PBE voters' strategies are as follows: If the time- $t$ incumbent office-holder adopts platform $y$, then each voter $x$ votes to re-elect the incumbent if and only if $L_{x}(y) \geq U_{x}$, where $U_{x}$ is the equilibrium expected continuation utility from selecting a new representative at random. In a PBE, the median voter is said to be decisive whenever an incumbent office-holder who adopts policy $y$ is re-elected if and only if $L_{0}(y) \geq U_{0}$, i.e., the incumbent office-holder is re-elected if and only if the median voter prefers the incumbent to the challenger.

\subsection{At-large selection of challengers}

With at-large selection of challengers, at the beginning of any period $t \geq 1$, the incumbent runs for re-election against a challenger drawn at random from $f(\cdot)$. We show in the Appendix that as long as the loss functions do not display too much risk aversion, there is a unique symmetric, stageundominated, stationary perfect Bayesian equilibrium. The equilibrium is completely summarized by thresholds $\{c, w\}$, where $0<w<c<a$. Candidates with centrist ideology $x \in[0, w]$ and extremist candidates $x \in[c, a]$ adopt their preferred policy $y=x$ when in office. Centrists are re-elected and extremists are ousted from office. Moderate candidates $x \in[w, c]$ do not adopt their preferred policy, as they would then lose office. They compromise and adopt the most extreme ideology that allows

\footnotetext{
${ }^{3}$ For notational simplicity, we abstract from ego rents for holding office. Our results extend qualitatively if we allow for ego rents.
} 
them to win re-election, i.e., they locate at $w$. The characterization is symmetric for $x<0$.

The equilibrium obeys the following Bellman equations:

$$
\begin{aligned}
& L_{0}(w)=U_{0}(c, w) \\
& L_{c}(w)=(1-\delta) L_{c}(c)+\delta U_{c}=\delta U_{c}(c, w) .
\end{aligned}
$$

The median voter is decisive: she is indifferent between re-electing a candidate that implements policy $w$ and electing the random challenger. The candidate $c$ is indifferent between implementing policy $w$ forever, or policy $c$ once and then be replaced by a random challenger.

For any citizen $x$, the PBE continuation expected value for electing the challenger is:

$$
\begin{aligned}
U_{x}(w, c)= & \int_{-a}^{-c}\left(L_{x}(y)(1-\delta)+\delta U_{x}\right) d F(y)+\int_{-c}^{-w} L_{x}(-w) d F(y) \\
& +\int_{-w}^{w} L_{x}(y) d F(y)+\int_{w}^{c} L_{x}(w) d F(y)+\int_{c}^{a}\left(L_{x}(y)(1-\delta)+\delta U_{c}\right) d F(y) .
\end{aligned}
$$

Throughout our analysis, we will assume that the parameters characterizing the economy are such that the median voter is decisive, and that candidates with more extreme ideologies are less willing to compromise, so that equilibrium is described by the set $\{c, w\}$. This amounts to assuming that citizens are not too risk averse. Theorem A1 in the appendix provides sufficient conditions for this to hold, extending Theorem 1 in Duggan (2000), which proves the result for linear loss $L_{x}(y)=-|x-y|$, with $a=1 / 2$ and uniform distribution $F$.

There are effectively two issues here. One deals with the decisiveness of the median voter. If the median voter prefers the incumbent representative, then so do all voters "closer" to the representative, so the incumbent must win the election. However, if the median voter prefers the challenger, she is not necessarily part of the winning coalition. In particular, if voters exhibit increasing risk aversion, so that the marginal disutility is increasing in the distance between a voter and a representative's location, a representative may be able to cobble together a winning coalition of voters with opposing extreme ideologies. In this case, the median voter is not decisive. For example, a representative who adopts a intermediate right-wing platform, may win the votes of all sufficiently right-wing voters, lose the vote from the median voter, yet win the votes from very risk-averse left-wing extremists 
who fear that the representative may be replaced by an even more extreme right-wing ideologue, thereby winning re-election. What underlies this is that the median voter effectively faces less risk than do voters with more extreme ideologies, because representatives cannot locate as far away from the median voter.

Formally, the condition that may be violated if $l$ is strictly concave is that $L_{x}(0)-U_{x}(c, w)$ be weakly decreasing in $x$, for any $w, c$. Our results do not depend on this assumption because the equilibrium still has the feature that representatives are retained in office if and only if their adopted policy $y$ belongs to a symmetric interval $[-w, w]$ around the median policy 0 . However, it simplifies the analysis because it permits us to focus on the preferred choice of the median voter.

The second issue is that if $l$ is too concave, the office-holder's choice of location may not be determined by a cutoff $c$. That is, it may not be the case that if an office-holder with ideology $x>0$ prefers not to compromise to win re-election then all office-holders with more extreme ideologies $x^{\prime}>x$ also prefer not to compromise. An extremist representative $x^{\prime}$ may fear being replaced by an opposing extremist by so much, that she is more willing to compromise and adopt the policy $w$ to win re-election than is the more moderate representative $x$. Formally, the condition that may violated if $l$ is strictly concave is that $L_{x}(w)-\delta U_{x}(x, w)$ be weakly decreasing in $x$, for any $w$.

\subsection{Party selection of candidates}

We contrast outcomes in the repeated election model with at-large selection of candidates - the standard modeling approach - with those that obtain when challenging candidates are chosen by opposing parties, $A$ and $B$. We initially assume that party $A$ includes all citizen-candidates with ideology $x<0$, and party $B$ all possible candidates with ideology $x>0$. In every $t$ election, the incumbent faces a challenger from the opposite party. That is, incumbents are always endorsed by their parties. Equivalently, we could assume that if the party does not endorse "its" incumbent, then voters who are indifferent between untried challengers from the two parties select the candidate chosen by the opposing party, rather than the candidate from the incumbent's party.

Again, we prove in the Appendix that, as long as voters are not too risk-averse, the symmetric, 
stage-undominated, stationary perfect Bayesian equilibrium is characterized by two thresholds: $v$ and $k$. An office-holder with a centrist ideology $x \in[-v, v]$ and those with extreme ideologies $x \in$ $[-a,-k] \cup[k, a]$ adopt their preferred policy $y=x$ when in office. Moderates are re-elected and extremists are ousted. Moderates office-holders with $x \in[-k,-v]$, and $x \in[v, k]$, adopt policies $-w$ and $w$ respectively, and are re-elected.

The Bellman equations characterizing the equilibrium are

$$
\begin{aligned}
& L_{0}(v)=\bar{U}_{0}(v, k)=\underline{U}_{0}(v, k), \\
& L_{k}(v)=(1-\delta) L_{k}(k)+\delta \underline{U}_{k}=\delta \underline{U}_{k}(v, k),
\end{aligned}
$$

For each new office-holder $k$, we need to distinguish the equilibrium expected continuation payoff when the next period's office-holder is selected from $k$ 's own party, denoted by $\bar{U}_{k}$, from the continuation payoff when the next period's office-holder is selected from the opposite party, $\underline{U}_{k}$.

$$
\begin{aligned}
& \underline{U}_{x}(v, k)=2 \int_{-a}^{-k}\left(L_{x}(y)(1-\delta)+\delta \bar{U}_{x}(v, k)\right) d F(y)+2 \int_{-k}^{-v} L_{x}(-v) d F(y)+2 \int_{0}^{v} L_{x}(y) d F(y) \\
& \bar{U}_{x}(v, k)=2 \int_{0}^{v} L_{x}(y) d F(y)+2 \int_{v}^{k} L_{x}(v) d F(y)+2 \int_{k}^{a}\left(L_{x}(y)(1-\delta)+\delta \underline{U}_{x}(v, k)\right) d F(y) .
\end{aligned}
$$

In contrast to at-large selection, the median voter is always decisive - an incumbent from (say) party $A$, can never be re-elected against the vote of the median citizen by a coalition of voters from the opposite extremes of the ideological spectrum. All right-wing extremists from party $B$ vote for the challenger, who is drawn from party $B$. Intuitively, an incumbent cannot be re-elected by a coalition of extremists, because the extremist members of the challenger's party prefer the challenger.

\subsection{Equilibrium and Welfare Comparison}

We now show that the introduction of parties makes candidates more willing to compromise. We proceed in separate Lemmata. We first show that an office-holder prefers to be replaced by a candidate randomly selected from "at large" to being replaced by a candidate from the opposing party. 
Lemma 1 Any office-holder $x$, and any equilibrium thresholds $(w, c)$, prefers to be replaced by a candidate from her own party to being replaced by a candidate from "at large" to being replaced by a candidate from the opposing party. That is, equilibrium payoffs are ranked as follows: $\underline{U}_{x}(w, c)<$ $U_{x}(w, c)<\bar{U}_{x}(w, c)$.

Proof. Suppose that $x>0$; the case for $x<0$ is analogous by symmetry. Subtracting equation (6) from equation (3), and using the symmetry of $f$, yields:

$$
\begin{gathered}
U_{x}-\underline{U}_{x}=\int_{-a}^{-c} \delta\left(U_{x}-\bar{U}_{x}\right) d F(y)-\int_{-a}^{-c}\left(L_{x}(y)(1-\delta)+\delta \bar{U}_{x}\right) d F(y)+\int_{0}^{w} L_{x}(y) d F(y) \\
+\int_{c}^{a}\left(L_{x}(y)(1-\delta)+\delta U_{x}\right) d F(y)-\int_{-c}^{-w} L_{x}(-w) d F(y)+\int_{w}^{c} L_{x}(w) d F(y)-\int_{-w}^{0} L_{x}(y) d F(y) \\
=\int_{c}^{a}\left[L_{x}(y)-L_{x}(-y)\right](1-\delta) d F(y)+\int_{w}^{c}\left[L_{x}(w)-L_{x}(-w)\right] d F(y) \\
\quad+\int_{0}^{w}\left[L_{x}(y)-L_{x}(-y)\right] d F(y)+2 \int_{c}^{a} \delta\left(U_{x}-\bar{U}_{x}\right) d F(y)
\end{gathered}
$$

Thus,

$$
\begin{aligned}
& \left(U_{x}-\underline{U}_{x}\right)\left(1-(2 \delta[F(a)-F(c)])^{2}\right)=\left[\int_{c}^{a}\left[L_{x}(y)-L_{x}(-y)\right](1-\delta) d F(y)\right. \\
& \left.+\int_{w}^{c}\left[L_{x}(w)-L_{x}(-w)\right] d F(y)+\int_{0}^{w}\left[L_{x}(y)-L_{x}(-y)\right] d F(y)\right](1-2 \delta[F(a)-F(c)]) .
\end{aligned}
$$

The result then follows because $L_{x}(y)>L_{x}(-y)$ for any $y>0$, because $\delta \leq 1$ and because $F(0)=$ $1 / 2$, and $c>0$ implies that $[F(a)-F(c)]<1 / 2$.

The proof that $U_{x}-\bar{U}_{x}>0$ is analogous.

We next prove that when comparing compromise set under party competition $[v, k]$ and at-large selection $[w, c]$, it must be either that $v<w$ and $k>c$, or that $v>w$ and $k<c$. That is, the compromise set is either enlarged or reduced at both extremes.

Lemma 2 When comparing the "at-large" selection compromise set $(w, c)$ and the party competition compromise set $(v, k)$ it must be the case that $(w-v)(c-k)<0$. 
Proof. Consider at-large selection first. By substituting the continuation utility (3) in the Belman equation (1) we obtain:

$$
0=-L_{0}(w)+2 \int_{c}^{a}\left(L_{0}(y)(1-\delta)+\delta L_{0}(w)\right) d F(y)+2 \int_{w}^{c} L_{0}(w) d F(y)+2 \int_{0}^{w} L_{0}(y) d F(y) .
$$

With party competition, substituting the continuation utility (6) in the Belman equation (4) yields:

$$
0=-L_{0}(v)+2 \int_{k}^{a}\left(L_{0}(y)(1-\delta)+\delta L_{0}(v)\right) d F(y)+2 \int_{v}^{k} L_{0}(v) d F(y)+2 \int_{0}^{v} L_{0}(y) d F(y) .
$$

Because the two equations have the same form, letting $\phi(w, c)$ equal the right-hand side, the result follows because:

$$
\begin{aligned}
\frac{d w}{d c} & =-\frac{\phi_{2}(w, c)}{\phi_{1}(w, c)}=-\frac{-2\left(L_{0}(c)(1-\delta)+\delta L_{0}(w)\right) f(c)+2 L_{0}(w) f(c)}{-L_{0}^{\prime}(w)+2 \int_{c}^{a} \delta L_{0}^{\prime}(w) d F(y)-2 L_{0}(w) f(w)+2 \int_{w}^{c} L_{0}^{\prime}(w) d F(y)+2 L_{0}(w) f(w)} \\
& =\left(-\frac{1}{L_{0}^{\prime}(w)}\right) \frac{2(1-\delta)\left[L_{0}(w)-L_{0}(c)\right] f(c)}{2 \delta[F(a)-F(c)]+2[F(c)-F(w)]-1}<0 \text { for } 0 \leq w \leq c,
\end{aligned}
$$

where the inequality follows because $L_{0}^{\prime}(w)<0, L_{0}(w)>L_{0}(c), f(c)>0$ and $2[F(a)-F(c)] \delta+$ $2[F(c)-F(w)]-1<-2[F(a)-F(w)]-1<0$, as $F(a)=1$ and $F(w)>1 / 2$ because $w>0$.

Lemma 2 uses the stationarity of the electoral environment to prove that party selection cannot cause voters to set such more demanding standards for re-election that they move in by more than increased willingness of extreme candidates to compromise. This result is central to our equilibrium and welfare comparison. Below we prove that the compromise interval is larger with party selection than with at-large selection. Combined with Lemma 2, this means both that with party selection more office-holders are willing to compromise, and that when they compromise, they take more centrist positions.

Proposition 1 Given that $L_{x}(v)-\delta \underline{U}_{x}(v, x)$ strictly decreases in $x$, the comparison of the compromise set under party competition $[v, k]$ and at-large selection $[w, c]$ is such that $v<w$ and $k>c$.

Proof. Suppose that $v=w$ and $c=k$. By Lemma $1, U_{x}(w, c)>\underline{U}_{x}(w, c)$ for any $w, c$. By substituting in the Belman equations (2), we obtain that $L_{c}(w)=l(|c-w|)=\delta U_{c}(w, c)>\delta \underline{U}_{c}(c, w)$. That is to say, for any $\varepsilon>0$ small enough, the candidate $c+\varepsilon$ prefers to adopt policy $w$ than $c+\varepsilon$. 
Holding $v=w$ fixed, the condition that the function $L_{x}(v)-\delta \underline{U}_{x}(v, x)$ of $x$ crosses zero only once and from above then implies that $k>c$. Given this, Lemma 2 implies that $v<w$.

Proposition 1 has immediate turnover and hence welfare implications. We now show that the introduction of parties makes all voters better off. Unlike most welfare analyses in this literature we do not consider only the effect on the median voter's welfare. Our welfare concept is Pareto efficiency.

Theorem 1 All voters prefer party competition to at-large selection of candidates.

The intuition for this result is simple. All citizens value insurance because they are weakly risk averse, and they discount utilities. Parties provide ex-ante insurance against extremist policies, because (a) $v<w$, i.e., there is less expected turn-over, and (b) $k>c$, i.e., positions are more moderate over all.

Remark (General Parties) Our results do not depend on the stark left-right division of potential candidates into parties. In particular, our results extend to a more general notion of parties that preserves symmetry. Now, each party is identified by a distribution of candidates, where $G_{B}$ firstorder stochastically dominates $G_{A}$ and the associated densities, $g_{A}$ and $g_{B}$, are symmetric in the sense that $g_{A}(x)=g_{B}(-x)$, for all $x$. When parties overlap, so the support of $G_{B}$ is $[-\hat{a}, a]$, with $-\hat{a}<0$, then the median voter is still decisive and policy holders are still retained in office if and only if their adopted policy $y$ belongs to a symmetric interval around the median policy of 0 . How are strategic outcomes affected? Most transparently, suppose that the left-most member of the rightwing $B$ party, $-\hat{a}$, is not so far to the left that she would cease to compromise to win re-election. Then, the effect of 'broadening' the ideological membership of each party enters through the reduced incentives of the marginal representative to compromise. In particular, right-wing members of party $B$ are less willing to compromise because if they represent their own ideology, they may be replaced by a right-wing member of the opposing party. As a result, the equilibrium is described by a set $\{\hat{v}, \hat{k}\}$, where $k>\hat{k}>c$ and $v<\hat{v}<w$, i.e., the equilibrium moves toward that associated with at-large selection. Somewhat counter-intuitively, it follows that all voters are made better off if the 
'ideological distance' between parties is raised so there is less overlap of ideologies (i.e., voter welfare rises with a rightward shift of $G_{B}$ on $\left.[-\hat{a}, 0]\right)^{4}$

\section{The 'Party Screening Effect'}

In the previous section we assumed that voters have no information about a challenger, save perhaps for her party affiliation. We now extend the analysis to allow for campaigning, through which candidates can disclose information about their ideologies before voting takes place. We shall assume that candidates come into the election with an imprecise, but verifiable, record of their ideological positions. This record is known by parties and the candidates running for office, but is not known by voters. We expand the basic model to let politicians enjoy ego rents $\rho$ for being in power. We assume that politicians can disclose their own, and their opponents' records at a cost $C$, which we assume is small relative to the benefit of holding office, i.e. $2 C<\delta \rho$.

For simplicity, we assume that the information contained in a candidate's record is coarse. Campaigning can only communicate whether the candidate's ideology is leftist or conservative, and whether the candidates is moderate or extremist, i.e. whether the candidate's ideology belongs to one of the following sets partitioning the ideology space: $E_{A}=[-a,-m), M_{A}=[-m, 0), M_{B}=(0, m]$ or $E_{B}=(m, a]$, where $E$ stands for extremist and $M$ for moderate, and the partition is symmetric around the median ideology $x=0$. Modelling imprecise verifiable signals as a partition of the ideology space simplifies the analysis.

In the party selection model, because each party knows its potential candidates' records, we assume that they can endorse candidates on the basis of their records. The timing of each election game is the following. First the challenging party chooses whether the endorsed candidate is selected

\footnotetext{
${ }^{4}$ If $\hat{a}$ is sufficiently large and close to $a$, equilibrium characterization becomes more involved. Whether an officeholder compromises or not depends on her party identity. Consider a party $A$ office-holder with ideology $x>0$. If she is ousted from office, she will be replaced from a challenger from party $B$, and such a candidate's ideology is likely to the right of the median voter. Hence, the party $A$ office-holder has a smaller incentive to compromise than under at-large selection. We must introduce thresholds $\underline{k}_{i}<0<\bar{k}_{i}$, for $A, B$. Party- $i$ office-holders compromise and adopt policy $-v$ if and only if $x \in\left[\underline{k}_{i},-v\right]$, and adopt policy $v$ if and only if $x \in\left[v, \underline{k}_{i}\right]$. Because $g_{A}$ is symmetric to $g_{B}$ around zero, and $G_{B}$ dominates $G_{A}$, we obtain that $\underline{k}_{A}<\underline{k}_{B}$ and $\bar{k}_{A}<\bar{k}_{B}$. Because the equilibrium is symmetric across parties, we have $\underline{k}_{A}=-\bar{k}_{B}, \underline{k}_{B}=-\bar{k}_{A}$, as well as $-\underline{k}_{A}=\bar{k}_{B},-\underline{k}_{B}=\bar{k}_{A}$. We conjecture that $v<w$, and that $\underline{k}_{A}<-c<\underline{k}_{B}$ and $\bar{k}_{A}<c<\bar{k}_{B}$.
} 
from the whole party or from either the moderate or the extremist subset only. Then each candidate decides whether to costly reveal her own or the opponent's verifiable records to voters. Finally, voters vote and select the new incumbent.

We show that in equilibrium, parties endorse moderate candidates whenever these candidates have chances to win. If they endorsed extremist candidates, they would be subject to the incumbent's negative advertisement and lose the election. As is usually the case, verifiable information is disclosed in equilibrium (see Milgrom 1981). Whenever the election matters for the equilibrium payoffs, party $A$ chooses a candidate in $M_{A}$ and $B$ chooses a candidate in $M_{B}$. Extremists never hold office. The equilibrium characterization of the previous section, determined by the thresholds $v, k$, therefore applies to this problem, once we restrict attention to candidates in $M_{A}$ and $M_{B}$.

Proposition 2 Under the conditions in Theorem A2, there is a unique stationary symmetric stageundominated equilibrium of the campaign model with party selection of candidates. In equilibrium, the median voter is decisive and extremist candidates are never in power. Office-holders with ideology $x \in[0, v] \cup(k, m]$ adopt policy $y=x$, and those with $x \in(v, k]$ compromise with policy $y=v$. officeholders are re-elected unless $x \in(k, m]$. Symmetrically for $x<0$. Letting $F^{*}(y)=F(y \mid y \in[-m, m])$, the thresholds $v, k$ are determined by the Belman equations (4) and (5), and for any $x>0$,

$$
\begin{aligned}
& \underline{U}_{x}(v, k)=2 \int_{-m}^{-k}\left(L_{x}(y)(1-\delta)+\delta \bar{U}_{x}(v, k)\right) d F^{*}(y)+2 \int_{-k}^{-v} L_{x}(-v) d F^{*}(y)+2 \int_{0}^{v} L_{x}(y) d F^{*}(y) \\
& \bar{U}_{x}(v, k)=2 \int_{0}^{v} L_{x}(y) d F^{*}(y)+2 \int_{v}^{k} L_{x}(v) d F^{*}(y)+2 \int_{k}^{m}\left(L_{x}(y)(1-\delta)+\delta \underline{U}_{x}(v, k)\right) d F^{*}(y) .
\end{aligned}
$$

The key feature of the result is the "party screening" effect that we have discussed. Under party competition, only moderate candidates are selected by parties and matter for the equilibrium characterization and welfare. For the sake of comparison, we first point out that an immediate consequence of Proposition 1 is that all citizens prefer party selection to at-large selection in the case that nature only selects moderate politicians. That is, the "party screening" effect complements and does not substitute for the "party-competition" effect.

Corollary 1 Suppose that with at-large selection, nature would select only moderate candidates. 
Then, in the campaign model, all voters prefer party selection to at-large selection of candidates.

The role of parties in our citizen-candidate repeated election model cannot be reduced to only providing information about the endorsed candidates, nor just to selecting moderate candidates. Party competition is essential in restraining policy choices by office-holders. Such a result depends on election repetition and does not arise in simpler static models. An office-holder is more willing to compromise (thus favoring the median voter and all citizens alike) under party competition, because she knows that if she loses the election she will be replaced by a candidate with an opposing ideology.

The corollary above does not prove that restricting selection to moderate candidates necessarily benefits all voters; it only shows that if choice is restricted to moderate candidates, then voters prefer party to at-large selection of candidates. Obviously, the "direct" effect of restricting attention to moderate candidates (i.e., holding $(c, w)$ fixed) is to raise the welfare of all voters. But, for example, restricting selection to moderate candidates could make candidates less willing to compromise, raising the likelihood of turnover, and hurting extreme voters. We now provide sufficient conditions with atlarge selection for this not to occur. It immediately follows that all voters prefer nature to select more moderate candidates, which, in turn, implies that voters prefer party selection to at-large selection in the campaign model.

Proposition 3 Suppose that $F$ is uniform and the loss function is homogenenous, i.e. $l(k|x-y|)=$ $g(k) l(|x-y|)$, where $g(k)>0$ for all $k$. Then the threshold function is linearly homogeneous $w(m)=m w(a)$ and $c(m)=m c(a)$. Hence the turnover probability is constant in $m$, whereas the welfare $U_{x}$ strictly decreases in $m$ for every $x$. Hence, in the campaign model, all voters prefer party selection to at-large selection of candidates.

\section{Conclusion}

We study the role of parties in a citizen-candidate repeated-elections model where voters have incomplete information. We have identified a novel "party competition" effect. Compared with "at-large" selection of candidates, party competition makes office-holders more willing to avoid taking extreme 
ideological stands. Incumbents would like to minimize the chances to be replaced by a challenger from the opposite party. Politicians follow party discipline, even in absence of a party-controlled reward mechanism. Voters of all ideologies benefit from the party-competition effect. Hence, our analysis provides a novel rationale for political parties: one of the main benefits of party competition is that it provides choice tied to clear ideological positions. The mere existence of a left-wing party discourages right-wing elected officials from drifting into extremism. When politicians have an (imperfect) informational advantage over voters, we additionally find a "party screening" effect. Parties select moderate candidates, because they understand that their candidate's ideological record can be verifiably disclosed through campaigning. This "party screening" effect complements and does not substitute for the "party competition" effect.

Our analysis can be extended in fruitful directions. As well as screening candidates according to their ideology, parties may also screen candidates according to their valence, i.e. competence, integrity, and so on. When valence is included in simple formulations of our model, equilibrium is described by valence-dependent thresholds. The median voter is willing to retain higher valence office-holders even if they adopt more extreme policies. At the same time, high-valence candidates need not compromise by as much to win re-election. This raises the possibility that the median voter may be made better off by dissemination of information about valence (so that high valence candidates can be selected); but extreme voters may be hurt because high valence candidates with extreme ideologies may win re-election. That is, voters with moderate and extreme ideologies trade off differently between ideology and valence in candidates - as all benefit in similar ways from valence, but candidates may locate further away from voters with extreme ideologies.

Finally, in the spirit of Bernhardt et al. (2004), it would be worthwhile to consider the impact of term limits. In simple versions of our model with a term limit of two, all sufficiently moderate voters continue to benefit from party selection, but it is possible to construct parameterizations in which party selection raises turnover of incumbents (i.e., lemma 2 may cease to hold as we have $v<w$, but $c>k$ ), in which case voters with more extreme ideologies are hurt by party selection if they have Euclidean preferences. 


\section{A Appendix: Omitted Proofs}

Theorem A1. There is a uniform bound $M$, such that if $M<l^{\prime \prime} \leq 0$, then $L_{x}(0)-U_{x}(c, w)$ weakly decreases in $x$, and $L_{x}(w)-\delta U_{x}(c, w)$ weakly decreases in $x$, for any $0<w<c<a$. As a result, there is a unique symmetric, stationary, stage-undominated equilibrium, and this equilibrium is determined by the thresholds $0<w<c<a$.

Proof. We first assume that the elected officials policy choice is described by the thresholds $0<w<c<a$, and show that the median voter is decisive, and sets the standard for re-election $w$.

Let the retrospective set of voter $x$ be defined as the positions $y$ implemented by an incumbent that $x$ will re-elect over a random challenger, hence $R_{x}=\left\{y \mid L_{x}(y)-U_{x}(c, w) \geq 0\right\}$. By proceeding in subsequent Lemmata, we will show that the retrospective set of the median voter $R_{0}$ is contained in the win set $W=[-w, w]$.

Lemma A1. For any $x \in[-a, a], 0 \in R_{x}$, i.e. zero belongs to the retrospective set of all agents.

Proof. Let $x \in[0, a]$, we need to show that $L_{x}(0)-U_{x}(c, w) \geq 0$. Note that $L_{x}(0)-U_{x}(c, w) \geq 0$ if and only if $\left(L_{x}(0)-U_{x}(c, w)\right)(1-2 \delta(F(a)-F(c))) \geq 0$,

$$
\begin{aligned}
& \left(L_{x}(0)-U_{x}(c, w)\right)(1-2 \delta(F(a)-F(c))) \\
= & \int_{0}^{w}-L_{x}(y)-L_{x}(-y)+2 L_{x}(0) d F(y) \\
& +\int_{w}^{c}-L_{x}(w)-L_{x}(-w)+2 L_{x}(0) d F(y)+\int_{c}^{a}\left(-L_{x}(y)-L_{x}(-y)+2 L_{x}(0)\right)(1-\delta) d F(y)
\end{aligned}
$$

We have that $L_{x}(y)=l(|x-y|), l^{\prime}(\cdot) \leq 0$ and $l^{\prime \prime}(\cdot) \leq 0$. Since $|x-y| \leq|x+y|$ for all $y \in[0, a]$, then $l(x)-l(|x-y|) \leq l(x)-l(|x+y|)$ the left side of the inequality is positive, the right side can be negative or positive, but in any case $-L_{x}(y)-L_{x}(-y)+2 L_{x}(0)=l(x)-l(|x-y|)+l(x)-l(|x+y|) \geq 0$. Therefore, the inequality holds and $0 \in R_{x}$ for all $x \in[0, a]$. Analogously, we can show that $0 \in R_{x}$ for all $x \in[-a, 0]$.

Lemma A2. For $x \in[-a, 0]$ we have that $\frac{\partial U_{x}(w, c)}{\partial x} \geq 0$ and for $x \in[0, a] \frac{\partial U_{x}(w, c)}{\partial x} \leq 0$.

Proof. Note that $\frac{\partial U_{x}(w, c)}{\partial x} \leq 0$ if and only if $\frac{\partial U_{x}(w, c)}{\partial x}(1-2 \delta(F(a)-F(c))) \leq 0$. Let $x>0$, then

$$
\begin{aligned}
& \frac{\partial U_{x}(w, c)}{\partial x}(1-2 \delta(F(a)-F(c))) \\
= & \int_{0}^{w} l^{\prime}(|x-y|) \frac{\partial(|x-y|)}{\partial x}+l^{\prime}(x+y) d F(y)+\int_{w}^{c} l^{\prime}(|x-w|) \frac{\partial(|x-w|)}{\partial x} \\
& +l^{\prime}(x+w) d F(y)+\int_{c}^{a}\left(l^{\prime}(|x-y|) \frac{\partial(|x-y|)}{\partial x}+l^{\prime}(x+y)\right)(1-\delta) d F(y) .
\end{aligned}
$$


Concavity of $l$ implies that $0 \geq l^{\prime}(|x-y|) \geq l^{\prime}(x+y)$ for all $y \in[0, a]$, and

$$
\frac{\partial(|x-y|)}{\partial x}=\left\{\begin{aligned}
1, & \text { if } \mathrm{x}>\mathrm{y} \\
-1, & \text { if } \mathrm{x}<\mathrm{y}
\end{aligned}\right.
$$

then $0 \geq l^{\prime}(|x-y|) \frac{\partial(|x-y|)}{\partial x}+l^{\prime}(x+y)$ for all $y \in[0, a]$. Therefore, for $x>0, \frac{\partial U_{x}(w, c)}{\partial x} \leq 0$. Analogously, we can show that for $x<0, \frac{\partial U_{x}(w, c)}{\partial x} \geq 0$.

Lemma A3. The retrospective set of the median voter $R_{0}$ is contained in the win set $W=[-w, w]$.

Proof. Let $x \in R_{0}$ and $x>0$ by Lemma $1,0 \in R_{y}$, then we must have that the lower extreme of the retrospective sets is less than zero, given that $y \in R_{y}$ for all $y$, then $x \in R_{y}$ for all $y \in[x, a]$. Note that the upper extreme of the retrospective set is given by $y+l^{-1}\left(U_{y}(w, c)\right)$, where $l^{-1}(\cdot)$ denotes the inverse function of $l(\cdot) ; l^{-1}(\cdot)$ is a decreasing function; and $l^{-1}: \Re^{-} \rightarrow \Re^{+}$. Lemma 2 implies that $U_{y}(w, c) \leq U_{0}(w, c)$, then $y+l^{-1}\left(U_{y}(w, c)\right) \geq 0+l^{-1}\left(U_{0}(w, c)\right)$, so $x \in R_{y}$ for all $y \in[0, x]$. Then, for any $x \in R_{0}$ and $x>0$ all $y \in[0, a]$ will vote for an incumbent that implements $x$ over a random challenger and therefore $x$ will win at least half the votes and belong to the win set.

Lemma A4. If $L_{x}(0)-U_{x}(w, c)$ decreases in $x$ for any $x>0$, then the win set $W$ is contained in the retrospective set of the median voter $R_{0}$.

Proof. We will show that if $y$ is not in $R_{0}$, then $y$ is not in the win set. Let $y$ not in $R_{0}$ and $y<0$, note that for any $x \in[0, a]$ the lower extreme of the retrospective set is given by $x-l^{-1}\left(U_{x}(w, c)\right)$. Given that $L_{x}(0)-U_{x}(w, c)$ decreases in $x$, for all $0<w<c<a$, it must be that $x-l^{-1}\left(U_{x}(w, c)\right)$ increases in $x$, for any $x>0$. Hence, we must have that $x-l^{-1}\left(U_{x}(w, c)\right) \geq 0-l^{-1}\left(U_{0}(w, c)\right) \geq y$, so $y$ is not in $R_{x}$ for all $x \in[0, a]$. Then, at least half the voters will vote against $y$ and $y$ will not belong to the win set. We can show that the condition implies that $x+l^{-1}\left(U_{x}(w, c)\right)$ increases for $x<0$, so analogously we can show that any $y$ not in $R_{0}$ and $y>0$ will not belong to the win set.

Lemma A5. There is a uniform bound $M$ such that if $M<l^{\prime \prime} \leq 0$, then $L_{x}(0)-U_{x}(w, c)$ decreases in $x$ for any $x>0$ and any $0<w<c<a$.

Proof. Because,

$$
\begin{aligned}
U_{x}(w, c)= & \frac{1}{1-\delta 2[F(a)-F(c)]}\left[\int_{-a}^{-c} L_{x}(y)(1-\delta) d F(y)+\int_{-c}^{-w} L_{x}(-w) d F(y)\right. \\
& \left.+\int_{-w}^{w} L_{x}(y) d F(y)+\int_{w}^{c} L_{x}(w) d F(y)+\int_{c}^{a} L_{x}(y)(1-\delta) d F(y)\right],
\end{aligned}
$$


it must be the case that:

$$
\begin{aligned}
& \frac{\partial}{\partial x} L_{x}(0)-\frac{1}{1-2 \delta[F(a)-F(c)]}\left[(1-\delta) \int_{-a}^{-c} \frac{\partial}{\partial x} L_{x}(y) d F(y)\right. \\
& +\int_{-c}^{-w} \frac{\partial}{\partial x} L_{x}(-w) d F(y)+\int_{-w}^{w} \frac{\partial}{\partial x} L_{x}(y) d F(y) \\
& \left.+\int_{w}^{c} \frac{\partial}{\partial x} L_{x}(w) d F(y)+(1-\delta) \int_{c}^{a} \frac{\partial}{\partial x} L_{x}(y) d F(y)\right]<0 .
\end{aligned}
$$

If $l^{\prime \prime}=0$, this quantity is indeed negative, because $\frac{\partial}{\partial x} L_{x}(y)$ is constant in $x, y$ and negative for $y<x$, $\frac{\partial}{\partial x} L_{x}(y)>0$ for all $y>x$, and

$$
\begin{aligned}
& \frac{1}{1-2 \delta[F(a)-F(c)]}\left[(1-\delta) \int_{-a}^{-c} d F(y)+\int_{-c}^{-w} d F(y)+\int_{-w}^{w} d F(y)+\int_{w}^{c} d F(y)+(1-\delta) \int_{c}^{a} d F(y)\right] \\
= & \frac{2(1-\delta)[F(a)-F(c)]+2[F(c)-F(0)]}{1-2 \delta[F(a)-F(c)]}=1, \text { when }[F(a)-F(c)]+[F(c)-F(0)]=1 / 2 .
\end{aligned}
$$

This implies that there is a uniform lower bound $M: 0<M<l^{\prime \prime}$ guaranteeing that $L_{x}(0)-U_{x}(w, c)$ decreases in $x$, for all $0<w<c<a$.

We finally conclude the proof by showing that, given the standard for re-election $w$ set by the median voter, the elected officials policy choice is described by the thresholds $0<w<c<a$.

Lemma A6. There is a uniform bound $M^{\prime}$ such that if $M^{\prime}<l^{\prime \prime} \leq 0$, then $L_{x}(w)-\delta U_{x}(c, w)$ decreases in $x$, for any $0<w<c<a$.

Proof. We need that for all $w: 0<w<a$, and all $x>w$, the following expression decreases in $x$ :

$$
\begin{aligned}
& L_{x}(w)-\delta U_{x}(c, w) \\
&= L_{x}(w)-\frac{\delta}{1-\delta 2[F(a)-F(c)]}\left[\int_{-a}^{-c} L_{x}(y)(1-\delta) d F(y)+\int_{-c}^{-w} L_{x}(-w) d F(y)\right. \\
&+\left.\int_{-w}^{w} L_{x}(y) d F(y)+\int_{w}^{c} L_{x}(w) d F(y)+\int_{c}^{a} L_{x}(y)(1-\delta) d F(y)\right] . \\
& \frac{\partial}{\partial x} L_{x}(w)-\frac{\delta}{1-\delta 2[F(a)-F(c)]}\left[(1-\delta) \int_{-a}^{-c} \frac{\partial}{\partial x} L_{x}(y) d F(y)+\int_{-c}^{-w} \frac{\partial}{\partial x} L_{x}(-w) d F(y)\right. \\
&\left.+\int_{-w}^{w} \frac{\partial}{\partial x} L_{x}(y) d F(y)+\int_{w}^{c} \frac{\partial}{\partial x} L_{x}(w) d F(y)+(1-\delta) \int_{c}^{a} \frac{\partial}{\partial x} L_{x}(y) d F(y)\right]
\end{aligned}
$$

Proceeding as in the proof of Lemma A.5, we obtain that if $l^{\prime \prime}=0$, then this expression is decreasing in $x$. Hence there is a uniform lower bound $M^{\prime}: 0<M^{\prime}<l^{\prime \prime}$ guaranteeing that $L_{x}(w)-\delta U_{x}(c, w)$ decreases in $x$, for all $0<w<c<a$. 
Theorem A2. There is a uniform bound $M$ such that if $M<l^{\prime \prime} \leq 0$, then $L_{x}(0)-\underline{U}_{x}(k, v)$ weakly decreases in $x$ and $L_{x}(v)-\delta \underline{U}_{x}(k, v)$ weakly decreases in $x$, for any $0<v<k<a$. As a result, there is a unique symmetric stationary stage-undominated equilibrium, and this equilibrium is determined by the thresholds $0<v<k<a$.

Proof. The proof that $L_{x}(v)-\delta \underline{U}_{x}(k, v)$ weakly decreases in $x$, for any $v$, and that as a result the elected politicians choice is described by thresholds $0<v<k<a$ is unchanged with respect to the at-large selection case. The proof that the retrospective set of the median voter $R_{0}$ is contained in the win set $W$ is unchanged with respect to the at-large selection case. The proof that the $W \subseteq R_{0}$ is as follows. Suppose that $y<0$ and $L_{0}(y)<U_{0}(v, k)$. Pick any $x \geq 0$, we calculate:

$$
\begin{aligned}
& \frac{\partial}{\partial x}\left[L_{x}(y)-\bar{U}_{x}(v, k)\right] \propto \frac{\partial}{\partial x}\left[2 \int_{0}^{v}\left[L_{x}(y)-L_{x}(t)\right] d F(t)+2 \int_{v}^{k}\left[L_{x}(y)-L_{x}(v)\right] d F(t)\right. \\
& +2 \int_{k}^{a}\left(\left[L_{x}(y)-L_{x}(t)\right](1-\delta)+\delta\left[2 \int_{-a}^{-k}\left(\left[L_{x}(y)-L_{x}(t)\right](1-\delta)\right) d F(t)\right.\right. \\
& \left.\left.\left.+2 \int_{-k}^{-v}\left[L_{x}(y)-L_{x}(-v)\right] d F(t)+2 \int_{-v}^{0}\left[L_{x}(y)-L_{x}(t)\right] d F(t)\right]\right) d F(t)\right] \\
= & +\frac{\partial}{\partial x}\left[2 \int_{0}^{v}\left[L_{x}(y)-L_{x}(t)+\delta\left[L_{x}(y)-L_{x}(-t)\right] 2[F(a)-F(k)]\right] d F(t)\right. \\
& +2 \int_{v}^{k}\left[L_{x}(y)-L_{x}(v)+\delta\left[L_{x}(y)-L_{x}(-v)\right] 2[F(a)-F(k)]\right] d F(t) \\
& \left.+(1-\delta) \int_{k}^{a}\left[L_{x}(y)-L_{x}(t)+\delta\left[L_{x}(y)-L_{x}(-t)\right] 2[F(a)-F(k)]\right] d F(t)\right] .
\end{aligned}
$$

Since $y<0$, it follows that $\frac{\partial}{\partial x}\left[L_{x}(y)-L_{x}(t)\right]<0$ for any $t>0$ and that $\left|\frac{\partial}{\partial x}\left[L_{x}(y)-L_{x}(t)\right]\right|>$ $\left|\frac{\partial}{\partial x}\left[L_{x}(y)-L_{x}(-t)\right]\right|$. This in turns, imply that the above quantity is positive.

Proof of Proposition 1. For any $x>0$, the case for $x<0$ is analogous, we need to compare the ex-ante "at large" welfare $U_{x}(c, w)$, with the party-competition ex-ante welfare

$$
\begin{aligned}
& U_{x}^{*}(k, v)=\frac{1}{2}\left[\underline{U}_{x}+\bar{U}_{x}\right]=\int_{-a}^{-k}\left(L_{x}(y)(1-\delta)+\delta \bar{U}_{x}\right) d F(y)+\int_{-k}^{-v} L_{x}(-v) d F(y) \\
& +\int_{-v}^{0} L_{x}(y) d F(y)+\int_{0}^{v} L_{x}(y) d F(y)+\int_{v}^{k} L_{x}(v) d F(y)+\int_{k}^{a}\left(L_{x}(y)(1-\delta)+\delta \underline{U}_{x}\right) d F(y) .
\end{aligned}
$$


Simple algebraic manipulations give:

$$
\begin{aligned}
& U_{x}^{*}(k, v)-U_{x}(c, w)=\frac{1}{2}\left[\underline{U}_{x}+\bar{U}_{x}\right]-U_{x}=\int_{k}^{a} \delta\left(\bar{U}_{x}+\underline{U}_{x}-2 U_{x}\right) d F(y) \\
& +\int_{c}^{k}\left[L_{x}(v)-L_{x}(y)(1-\delta)-\delta U_{x}\right] d F(y)+\int_{c}^{k}\left[L_{x}(-v)-L_{x}(-y)(1-\delta)-\delta U_{x}\right] d F(y) \\
& +\int_{w}^{c}\left[L_{x}(-v)-L_{x}(-w)\right] d F(y)+\int_{w}^{c}\left[L_{x}(v)-L_{x}(w)\right] d F(y) \\
& +\int_{v}^{w}\left[L_{x}(-v)-L_{x}(-y)\right] d F(y)+\int_{v}^{w}\left[L_{x}(v)-L_{x}(y)\right] d F(y),
\end{aligned}
$$

where we use the order $0<v<w<c<k$, to simplify integral expressions. Thus,

$$
\begin{aligned}
& U^{*}(k, v)-U_{x}(c, w) \propto \Phi \equiv \int_{c}^{k}\left[L_{x}(v)-L_{x}(y)(1-\delta)-\delta U_{x}\right] d F(y) \\
& +\int_{c}^{k}\left[L_{x}(-v)-L_{x}(-y)(1-\delta)-\delta U_{x}\right] d F(y)+\int_{v}^{w}\left[L_{x}(-v)-L_{x}(-y)\right] d F(y) \\
& +\int_{v}^{w}\left[L_{x}(v)-L_{x}(y)\right] d F(y)+\int_{w}^{c}\left[L_{x}(-v)-L_{x}(-w)\right] d F(y)+\int_{w}^{c}\left[L_{x}(v)-L_{x}(w)\right] d F(y) .
\end{aligned}
$$

For any $y: v<y \leq c$, we know that $L_{x}(-v)-L_{x}(-y) \geq 0$, by monotonicity of the function $L_{x}$ for negative policies, and that $L_{x}(-v)-L_{x}(-y) \geq\left|L_{x}(v)-L_{x}(y)\right|$, because $x>0$. Hence

$$
\Phi \geq \delta[F(k)-F(c)] \Psi_{x}=\delta \int_{c}^{k}\left[L_{x}(v)-U_{x}\right] d F(y)+\delta \int_{c}^{k}\left[L_{x}(-v)-U_{x}\right] d F(y) .
$$

Let $x$ momentarily be the median voter: Substituting in this equation the Belman equation (1), and using the symmetry of $L_{0}$ around zero, we obtain:

$$
\Psi_{x}=L_{0}(v)-L_{0}(w)+L_{0}(v)-L_{0}(w)>0
$$

because $v<w$ and hence $L_{0}(v)>L_{0}(w)$.

Now consider all other voters $x$. Note that:

$U_{x}=\frac{\int_{c}^{a}\left[L_{x}(-y)+L_{x}(y)\right](1-\delta) d F(y)+\int_{w}^{c}\left[L_{x}(-w)+L_{x}(w)\right] d F(y)+\int_{0}^{w}\left[L_{x}(-y)+L_{x}(y)\right] d F(y)}{1-2 \delta[F(a)-F(c)]}$

Hence:

$$
\begin{gathered}
\Psi_{x}=L_{x}(v)+L_{x}(-v)-2 U_{x} \\
\propto \Upsilon_{x}=(1-2 \delta[F(a)-F(c)])\left[L_{x}(v)+L_{x}(-v)\right]-(1-2 \delta[F(a)-F(c)]) 2 U_{x} \\
=-2 \int_{c}^{a}\left[L_{x}(y)+L_{x}(-y)\right](1-\delta) d F(y)-2 \delta[F(a)-F(c)]\left[L_{x}(v)+L_{x}(-v)\right] \\
-2 \int_{w}^{c}\left[L_{x}(w)+L_{x}(-w)\right] d F(y)-\int_{0}^{w} 2\left[L_{x}(y)+L_{x}(-y)\right] d F(y)+\left[L_{x}(v)+L_{x}(-v)\right]
\end{gathered}
$$




$$
\begin{aligned}
= & -2(1-\delta) \int_{c}^{a}\left[L_{x}(y)+L_{x}(-y)-\left[L_{x}(v)+L_{x}(-v)\right]\right] d F(y) \\
& -2\left[L_{x}(w)+L_{x}(-w)-\left[L_{x}(v)+L_{x}(-v)\right]\right][F(c)-F(w)] \\
& -2 \int_{0}^{w}\left[L_{x}(y)+L_{x}(-y)-\left[L_{x}(v)+L_{x}(-v)\right]\right] d F(y) .
\end{aligned}
$$

For any $y$, note that $\frac{d}{d x}\left[L_{x}(y)+L_{x}(-y)\right] \leq 0$, that $\frac{d^{2}}{d x d y}\left[L_{x}(y)+L_{x}(-y)\right] \geq 0$ if $L=-k|x-y|$ for any $k>0$ and that for fixed $l^{\prime}(|x-y|)$ and $l^{\prime}(|x+y|), \frac{d^{2}}{d x d y}\left[L_{x}(y)+L_{x}(-y)\right]$ is smaller the smaller are $l^{\prime \prime}(|x-y|)$ and $l^{\prime \prime}(|x+y|)$.

After inspecting the above equation, we conclude that we only need to show that $\Psi_{x}>0$ for all $x$, for the case that $l^{\prime \prime}=0$. Indeed, we find:

$$
\Upsilon_{x}= \begin{cases}-2 \int_{x}^{a}[2 x-2 y](1-\delta) d F(y)>0, & \text { for } 0<v<w<c<x<a, \\ -2 \int_{c}^{a}[2 x-2 y](1-\delta) d F(y)>0, & \text { for } 0<v<w<x<c<a, \\ -2 \int_{c}^{a}[2 x-2 y](1-\delta) d F(y)-2[2 x-2 w][F(c)-F(w)]+ & \\ -2 \int_{x}^{w}[2 x-2 y] d F(y)>0 & \text { for } v<x<w<c<a, \\ -2 \int_{c}^{a}[2 v-2 y](1-\delta) d F(y)-2[2 v-2 w][F(c)-F(w)]+ & \\ -2 \int_{v}^{w}[2 v-2 y] d F(y)-2 \int_{0}^{v}[2 v-2 x] d F(y)>0 & \text { for } 0<x<v<w<c<a,\end{cases}
$$

where the last expression is positive because increasing in $x$ and because $\Upsilon_{0}>0$.

Proof of Proposition 2. Suppose that the incumbent is of party $B$ and adopts policy $y>0$. Let $U_{x^{\prime}}\left(E_{A}\right), U_{x^{\prime}}\left(M_{A}\right), U_{x^{\prime}}(A)$ be respectively the equilibrium continuation value to a voter $x^{\prime}$ of electing a challenger with ideology $x \in E_{A}, x \in M_{A}$, and $x \in[-a, 0]$. Let $v_{E}$ and $v_{M}$ solve $L_{0}\left(v_{E}\right)=U_{0}\left(E_{A}\right)$ and $L_{0}\left(v_{M}\right)=U_{0}\left(M_{A}\right)$.

Lemma A7. If challengers may be both moderate $\left(x \in M_{A}\right)$ and extremist $\left(x \in E_{A}\right)$, then the incumbent wins the election in equilibrium if $0 \leq y \leq v_{M}$, or if $v_{M}<y \leq v_{E}$ and $x \in E_{A}$, whereas she loses if $v_{E}<y \leq a$, or if $v_{M}<y \leq v_{E}$ and $x \in M_{A}$.

Proof. Consider any stationary stage-undominated equilibrium where the median voter is decisive. When the voters know that $x \in E_{A}$, the incumbent wins the election if and only if $L_{0}(y) \geq U_{0}\left(E_{A}\right)$, i.e. $y \leq v_{E}$. If it is disclosed that $x \in M_{A}$, the incumbent wins whenever $L_{0}(y) \geq U_{0}\left(M_{A}\right)$, i.e. $y \leq v_{M}$. If the voters are uninformed, she retains office when $L_{0}(y) \geq U_{0}(A)$, i.e. $y \leq v_{A}$ where $L_{0}\left(v_{A}\right)=U_{0}(A)$. The record of the incumbent is immaterial.

In any stationary equilibrium, $U_{0}\left(E_{A}\right)<U_{0}(A)<U_{0}\left(M_{A}\right)$. Suppose in fact that the challenger $A$ is elected. Her policy choice $y=p(x)$ depends only on her ideology $x<0$, and not on whether her record has been revealed. By the single-crossing property of the loss functions $L_{x}(y)=l(|x-y|)$, the policy $p(x)$ is weakly increasing in $x$. Hence, the distribution $x \mid\left\{x \in M_{A}\right\}$ first-order stochastically 
dominates $x \mid\{x \in[-a, 0]\}$ dominates $x \mid\left\{x \in E_{A}\right\}$. To complete the argument, note that the policy choices of future challengers do not depend on the challenger's record, and that $L_{0}(y)$ function is increasing in $y$, for $y<0$

Because $U_{0}\left(E_{A}\right)<U_{0}(A)<U_{0}\left(M_{A}\right)$, it follows that $v_{M}<v_{A}<v_{E}$. When $0 \leq y \leq v_{M}$ the incumbent wins the election regardless of the challenger's record, when $y>v_{E}$, the challenger wins regardless of her record. When $y \in\left(v_{A}, v_{E}\right]$ the incumbent wins unless it is disclosed that $x \in M_{A}$. When $y \in\left(v_{M}, v_{A}\right]$ the challenger wins unless it is disclosed that $x \in E_{A}$.

Because the campaigning cost $C$ is smaller than $\delta \rho$, it follows that (i) when $y \in\left(v_{A}, v_{E}\right]$ and $x \in M_{A}$, the challenger will disclose that $x \in M_{A}$, and (ii) when $y \in\left(v_{M}, v_{A}\right]$ and $x \in E_{A}$, the incumbent will disclose that $x \in E_{A}$. Hence, the incumbent wins the election if $0 \leq y \leq v_{M}$, or if $v_{M}<y \leq v_{E}$ and $x \in E_{A}$, whereas she loses if $v_{E}<y \leq a$, or if $v_{M}<y \leq v_{E}$ and $x \in M_{A}$.

Anticipating this, party $A$ unanimously endorses a candidate with record $M_{A}$ whenever the incumbent's policy $y \in\left(v_{M}, v_{E}\right]$. To see that all citizens $x<0$ prefer to have a candidate with record $M_{A}$ in power, rather than retaining the incumbent $y$, note that because $y \leq v_{E}$, the median voter prefers to elect the candidate with record $M_{A}$ instead of the incumbent. A fortiori, this is also the preference of all voters $x<0$. When $y \leq v_{M}$ or $y \geq v_{E}$, the challenger record is not revealed in the election, and the party choice is irrelevant for our proof.

Because $U_{0}\left(E_{A}\right)<U_{0}(A)<U_{0}\left(M_{A}\right)$, in the time-0 election, both parties select a moderate candidate. In fact, if party (say) $B$ choose a candidate $x \in E_{B}$, the best response of party $A$ would be to select a candidate $x \in M_{A}$. Because $2 C<\delta \rho$, the party- $A$ candidate would reveal that $x \in E_{B}$ and that $x \in M_{A}$ and win the election.

This concludes that, in equilibrium, extremist candidates are never elected, and that the incumbent will lose the election to a moderate challenger if selecting policy $y>v_{M}$. This means that extremist candidates must be disregarded by the analysis. Hence, the equilibrium is characterized by the thresholds $v_{M}$ and $k_{M}$ such that $L_{0}\left(v_{M}\right)=U_{0}\left(M_{A}\right)$ and $L_{k_{M}}\left(v_{M}\right)=\delta U_{k_{M}}\left(M_{A}\right)$.

Proof of Proposition 3. Consider the equations characterizing equilibrium

$$
L_{0}(m w)=U_{0}(m c, m w), \quad L_{m c}(m w)=\delta U_{m c}(m c, m w) .
$$

Hence,

$$
L_{m c}(m w)=\frac{1}{2 m[1-\delta[1-c] / 2]}\left[\begin{array}{c}
\int_{0}^{m w}\left[L_{m c}(y)+L_{m c}(-y)\right] d y \\
+\int_{m w}^{m c}\left[L_{m c}(m w)+L_{m c}(-m w)\right] d y \\
+(1-\delta) \int_{m c}^{a m}\left[L_{m c}(y)+L_{m c}(-y)\right] d y
\end{array}\right]
$$




$$
\begin{gathered}
l(|m w-m c|)=\frac{\delta}{2 m[1-\delta[1-c] / 2]}\left[\begin{array}{c}
\int_{0}^{m w}[l(|m c-y|)+l(|m c+y|)] d y \\
+\int_{m w}^{m c}[l(|m c-m w|)+l(|m c+m w|)] d y \\
+(1-\delta) \int_{m c}^{a m}[l(|m c-y|)+l(|m c+y|] d y
\end{array}\right], \\
l(m|w-c|)=\frac{\delta}{2 m[1-\delta[1-c] / 2]}\left[\begin{array}{c}
\int_{0}^{w}[l(m|c-y|)+l(m|c+y|)] m d y \\
+\int_{w}^{c}[l(m|c-w|)+l(m|c+w|)] m d y \\
+(1-\delta) \int_{c}^{1}[l(m|c-y|)+l(m|c+y|] m d y
\end{array}\right], \\
l(m|w-c|)=\frac{\delta}{2[1-\delta[1-c] / 2]}\left[\begin{array}{c}
\int_{0}^{w}[l(m|c-y|)+l(m|c+y|)] d y \\
+\int_{w}^{c}[l(m|c-w|)+l(m|c+w|)] d y \\
+(1-\delta) \int_{c}^{a}[l(m|c-y|)+l(m|c+y|)] d y
\end{array}\right]
\end{gathered}
$$

Suppose that $l$ is a homogeneous function: $l(m|w-c|)=g(m) l(|w-c|)$. Then we obtain:

$$
g(m) l(|w-c|)=\frac{\delta}{2[1-\delta[1-c] / 2]}\left[\begin{array}{c}
g(m) \int_{0}^{w}[l(|c-y|)+l(|c+y|)] d y \\
+g(m) \int_{w}^{c}[l(|c-w|)+l(|c+w|)] d y \\
+(1-\delta) g(m) \int_{c}^{a}[l(|c-y|)+l(|c+y|)] d y
\end{array}\right]
$$

and hence

$$
l(|w-c|)=\frac{\delta}{2[1-\delta[1-c] / 2]}\left[\begin{array}{c}
\int_{0}^{w}[l(|c-y|)+l(|c+y|)] d y \\
+\int_{w}^{c}[l(|c-w|)+l(|c+w|)] d y \\
+(1-\delta) \int_{c}^{a}[l(|c-y|)+l(|c+y|)] d y
\end{array}\right]
$$

analogously, we obtain:

$$
l(|w|)=\frac{1}{2[1-\delta[1-c] / 2]}\left[\begin{array}{c}
\int_{0}^{w}[l(|-y|)+l(|y|)] d y \\
+\int_{w}^{c}[l(|-w|)+l(|w|)] d y \\
+(1-\delta) \int_{c}^{a}[l(|-y|)+l(|y|)] d y
\end{array}\right],
$$

and this verifies the result that $w(m)=m w$, and that $c(m)=c m$. Further, consider

$$
\begin{gathered}
\delta \\
U_{x}(m w, m c)=\frac{\delta}{2 m[1-\delta[1-c] / 2]}\left[\begin{array}{c}
\int_{0}^{m w}\left[L_{x}(y)+L_{x}(-y)\right] d y+ \\
\int_{m w}^{m c}\left[L_{x}(m w)+L_{x}(-m w)\right] d y \\
+(1-\delta) \int_{m c}^{a m}\left[L_{x}(y)+L_{x}(-y)\right] d y
\end{array}\right] . \\
U_{x}(m w, m c)=\frac{\delta}{2[1-\delta[1-c] / 2]}\left[\begin{array}{c}
\int_{0}^{w}[l(|x-m y|)+l(|x+m y|)] d y+ \\
\int_{w}^{c}[l(|x-m v|+l(|x+m v|)] d y \\
+(1-\delta) \int_{c}^{a}[l(|x-m y|)+l(|x+m y|)] d y
\end{array}\right] .
\end{gathered}
$$

Because $l^{\prime \prime} \leq 0$, it follows that $\partial[l(|x-m y|)+l(|x+m y|)] / \partial m<0$ and hence that $\partial U_{x} / \partial m$. 


\section{References}

[1] Ashworth, Scott and Ethan Bueno de Mesquita (2004): "Party Discipline, Executive Power, and Ideological Balance" mimeo, Princeton University.

[2] Austen-Smith, David and Jeffrey S. Banks (1989): "Electoral Accountability and Incumbency," in Models of Strategic Choice in Politics, ed. by Peter Ordeshook. Ann Arbor: University of Michigan Press.

[3] Banks, Jeffrey S. and John Duggan (2001), "A Multidimensional Model of Repeated Elections," mimeo, University of Rochester.

[4] Banks, Jeffrey S. and Rangarajan K. Sundaram (1998), "Optimal Retention in Agency Problems, Journal of Economic Theory, 82, p.293-323.

[5] Banks Jeffrey S. and Rangarajan K. Sundaram (1993), "Moral Hazard and Adverse Selection in a Model of Repeated Elections", in Political Economy: Institutions, Information, Competition and Representation, W. Barnett et al. editors, New York, Cambridge University Press.

[6] Bernhardt, Dan, Sangita Dubey and Eric Hughson (2004): "Term Limits and Pork Barrel Politics", Journal of Public Economics, 2383-2422.

[7] Downs, Anthony (1957): An Economic Theory of Democracy, New York: Harper and Row.

[8] Duggan, John (2000): "Repeated Elections with Asymmetric Information, Economics and Politics, 12, 109-135.

[9] Feddersen Tim (1993): "Coalition-proof Nash Equilibria in a Model of Costly Voting under Plurality Rule," mimeo.

[10] Ferejohn, John (1986): "Incumbent Performance and Electoral Control," Public Choice, 43: $5-25$.

[11] Fiorina, Morris (1981): Retrospective Voting in American National Elections, Cambridge University Press, New Haven, CT.

[12] Jackson, Matt and Boaz Moselle (2001), "Coalition and Party Formation in a Legislative Voting Game" Journal of Economic Theory, 103: 1-39.

[13] Levy, Gilat (2004): "A Model of Political Parties", Journal of Economic Theory, 115: 250-277. 
[14] Lindbeck, Assar and Jorgen Weibull (1993): "A Model of Political Equilibrium in a Representative Democracy," Journal of Public Economics 51: 195-209.

[15] Milgrom, Paul R. (1981): "Good News and Bad News: Representation Theorems and Applications," Bell Journal of Economics, 12: 380-391.

[16] Morelli, Massimo (2004): "Party Formation and Policy Outcomes under Different Electoral Systems," Review of Economic Studies 71: 829-853.

[17] Osborne, Martin J. and Rabee Tourky (2003): "Party Formation in Collective DecisionMaking." mimeo.

[18] Persson, Torsten, Gerard Roland and Guido Tabellini (2003): "How do electoral rules shape party structures, government coalitions, and economic policies?," mimeo.

[19] Reed, Robert (1989): "Information in Political Markets: A Little Knowledge can be a Dangerous Thing," Journal of Law, Economics, and Organization, 5: 355-373.

[20] Reed, Robert (1994): "A Retrospective Voting Model with Heterogeneous Politicians ", Economics and Politics, 6: 39-58.

[21] Snyder, James M. and Michael M. Ting (2002): "An Informational Rationale for Political Parties," American Journal of Political Science 46: 90-110. 